\title{
IMPLEMENTASI MESIN PEMASAK NIRA AREN DILENGKAPI TEKNOLOGI "DUKASTO" GUNA MENINGKATKAN PRODUKTIVITAS GULA AREN DI DESA PLEDOKAN KECAMATAN SUMOWONO KABUPATEN SEMARANG
}

\author{
Asri Nurdiana ${ }^{1 *}$, Ida Hayu Dwimawanti ${ }^{2}$, Agus Setyawan ${ }^{3}$ \\ ${ }^{1}$ Departement of Civil Engineering and Architecture design, Faculty of Vocational School, \\ Diponegoro University, Semarang, 50275, Indonesia. \\ ${ }^{2}$ Department of Relation Public, Faculty of Social and Politics, \\ Diponegoro University, Semarang, 50275, Indonesia. \\ ${ }^{3}$ Departement of Physics, Faculty of Science and Mathematics, \\ Diponegoro University, Semarang, 50275, Indonesia. \\ ${ }^{*}$ Korespondensi: fahmiarifan80@gmail.com
}

Diterima 30 September 2019 / Disetujui 2 November 2019

\begin{abstract}
ABSTRAK
Gula aren adalah pemanis yang dibuat dari nira yang berasal dari tandan bunga jantan pohon enau. Gula aren selalu menjadi bahan baku yang digunakan hampir di seluruh bahan makanan. Oleh karena itulah yang menjadi dasar pembukaan usaha kegiatan mandiri (UKM) di daerah Sumowono, Semarang. Proses pencampuran bahan masih dilakukan dengan alat yang sangat sederhana, sehingga prosesnya juga membutuhkan waktu cukup lama. Oleh karena itu, dibutuhkan alat bejana pemasakan nira lengkap dengan peralatan pengadukan, penataan tungku dengan menggunakan bahan bahan bakar gas atau alat pengisap debu, sehingga kualitas gula aren dapat meningkat. Dengan demikian gula aren yang dihasilkan mempunyai kualitas 1 , sedangkan yang rafinasi gula aren dapat dihasilkan gula aren dengan kualitas 2, sehingga sesuai dengan apa yang telah ditargetkan, dimana pasar gula mareh maupun gula aren rafinasi meningkat $20 \%$ tiap tahunnya.
\end{abstract}

Kata Kunci: nira, bejana pemasak, gula aren

\section{PENDAHULUAN}

Produk pertanian pada umumnya dihasilkan sebagai bahan mentah yang mempunyai sifat mudah rusak dan tidak tahan lama, sehingga memerlukan adanya suatu proses pengolahan agar dapat meningkatkan nilai tambah melalui produk olahan dalam bentuk setengah jadi maupun barang jadi. Oleh karena itu, diperlukan suatu industri pengolahan untuk mengolah hasil pertanian tersebut.
Pengolahan hasil pertanian bertujuan untuk mengawetkan, menyajikan produk menjadi lebih siap dikonsumsi serta meningkatkan kualitas produk sehingga dapat disajikan dalam bentuk yang lebih baik dan dapat lebih memberikan kepuasan kepada konsumen. Terdapat banyak produk pertanian yang sangat potensial untuk ditingkatkan nilainya sehingga dapat memperoleh harga jual yang lebih tinggi (Widodo, 2003). 
Salah satu industri pengolahan yang berbahan baku produk pertanian adalah industri gula aren atau dikenal dengan nama gula jawa. Gula aren merupakan jenis gula yang terbuat dari nira kelapa yaitu cairan yang dihasilkan dari penyadapan mayang tanaman kelapa. Keadaan alam Indonesia yang beriklim tropis membuat tanaman kelapa banyak tumbuh dan berkembang di Indonesia khususnya di sepanjang daerah pantai, karena tanaman kelapa dapat tumbuh dengan baik di lingkungan yang bersuhu kurang lebih $27^{\circ} \mathrm{C}$ dan pada ketinggian tempat 0-450 meter dpl.

Gula aren adalah pemanis yang dibuat dari nira yang berasal dari tandan bungan jantan pohon enau. Gula aren diasosiasikan dengan segala jenis gula ysng dibuat dari nira, yaitu cairan yang dikeluarkan dari bunga pohon dari keluarga palma, seperti kelapa,aren dan siwalan. Gula aren selalu menjadi bahan baku yang didunakan hampir di seluruh bahan makanan, oleh karenanya hal itulah yang menjadi dasar pembukaan usaha kegiatan mandiri (UKM) yang berdiri di daerah Sumowono, Semarang.

Selain prospek pemasaran yang mudah, bahan baku yang digunakan juga mudah didapatkan. Bahan baku diambil dari nira pohon kelapa dengan jalan menyadap pohon tersebut. Pada kecamatan Sumowono semarang terdapat dua UKM yaitu UKM Gula Aren Yasripun yang berada di RT 4/RW 1 Pledokan Kecamatan Sumowono Kabupaten Semarang. Dari survey lapangan, salah seorang produsen bisa menyediakan 10 $\mathrm{kg} / \mathrm{hr}$ dari $200 \mathrm{~kg} / \mathrm{hr}$ yang sebetulnya dibutuhkan oleh pelanggannya dari Bandung, yang memasok kebutuhan caira nira kelapa dari Banjarnegara dan Kebumen. Setiap bulan, produsen tersebut juga masih harus memasok kurang lebih $300 \mathrm{~kg}$ yang ada di Semarang dan sekitarnya, masing-masing kurang lebih 50 $\mathrm{kg} / \mathrm{hr}$ untuk toko, di samping penjualan yang langsung dilakukan oleh pengusaha kepada pelanggan. Sedangkan permintaan yang semakin meningkat menjelang hari raya sebanyak dua kali per tahun belum bisa terlayani. Demikian juga permintaan dari Jawa Barat dan Jakarta belum bisa terlayani.

\section{METODE KEGIATAN}

Metode atau solusi yang ditawarkan untuk UKM Gula Aren adalah dengan menggunakan bejana pemasakan nira lengkap dengan peralatan pengadukan, penataan tungku dengan menggunakan bahan bahan bakar gas atau alat pengisap debu sehingga kualitas gula aren dapat meningkat. Sedangkan bila masih terjadi produk kurang baik maka produk akan di buat gula rafinasi. Secara umum dibagi menjadi empat tahap, meliputi: desain pabrikasi alat, pelatihan penggunaan alat pada UKM sasaran, pengoperasian alat dan monitoring serta uji keandalan mesin.

Pelaksanaan pengujian bejana pemasak yang dilengkapi dengan motor pengaduk dan cerobong gas Dari tinjauan lapangan rata produsen Gula Aren adalah petani dan ibu rumah tangga, maka kendala yang dihadapi rata-rata sama, modal dan kualitas belum sama, untuk itu disepakati permodalan oleh Dinas Koperasi dan UMKM Kabupaten Semarang. Sedangkan untuk kontrol kualitas diharapkan Fakultas Teknik Undip. Sehingga diperlukan bejana pemasakan nira lengkap dengan peralatan pengadukan, penataan tungku dengan menggunakan bahan bahan bakar gas atau alat pengisap debu sehingga kualitas gula aren dapat meningkat.

\section{HASIL DAN PEMBAHASAN}

Pengembangan dan penerapan alat bejana pemasakan dengan desain alat 
mesin pengaduk dan pemanas otomatis yang dilengkapi poros pengaduk dengan Pelatihan penggunaan alat bejana pemasakan dengan pengaduk dan pemanas otomatis pada UKM Gula Aren Sumowono diharapkan anggota UKM juga dapat memperoleh bekal dalam perancangan dan pabrikasi alat bejana pemasakan yang dilengkapi pengadukan dan pemanasan otomatis.

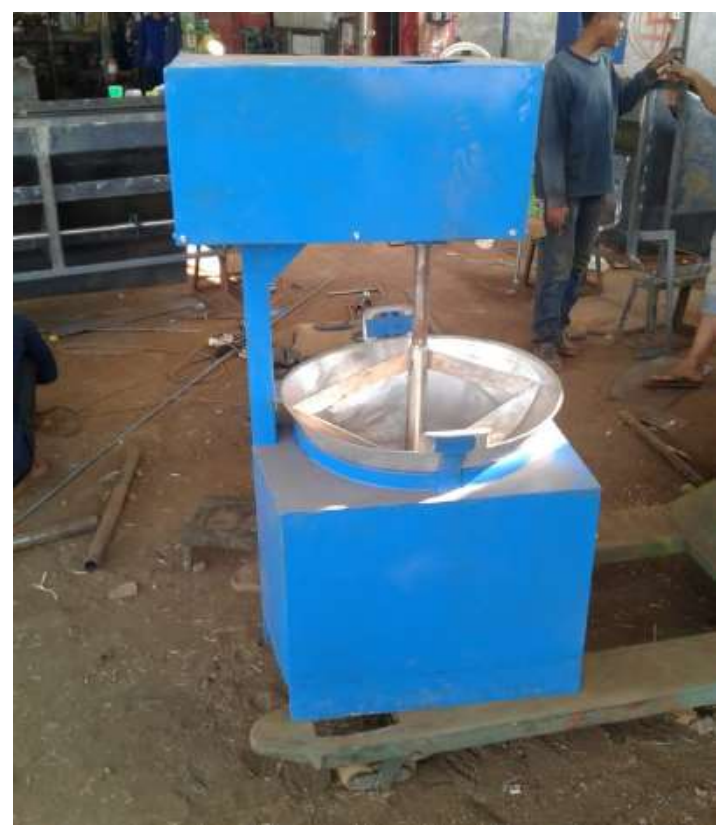

Gambar 1. Mesin pengaduk dan pemanas otomatis

Pada proses pencampuran bahan produksi memakai pengaduk manual. Proses pencampuran bahan masih dilakukan dengan alat yang sangat sederhana sehingga prosesnya juga membutuhkan waktu cukup lama. Oleh karena itu dibutuhkan alat bejana pemasakan nira lengkap dengan peralatan pengadukan, penataan tungku dengan menggunakan bahan bahan bakar gas atau alat pengisap debu sehingga kualitas gula aren dapat meningkat. Sedangkan masalah lain pada UKM Gula Aren adalah kualitas gula yang belum bisa disamakan karena proses produksinya belum bisa distandarkan. Oleh karena itu produsen harus segera menentukan standar kualitas dan prosedur untuk mengontrol kualitas sehingga kualitas gula aren dapat terjaga. Alat bejana pemasakan yang dilengkapi pengaduk dan pemanas otomatis hasil desain dan pabrikasi akan dioperasikan di UKM Gula Aren Sumowono yang akan memproduksi gula kualitas 1 , gula kualitas 2, gula kualitas 3

\section{KESIMPULAN}

Bejana pemasakan yang dilengkapi dengan pengaduk dan pemanas otomatis dioperasikan di UKM Gula Aren Sumowono mampu meningkatkan produksi dan memberikan tingkat efisensi dan efektif dalam memproduksi gula aren sehingga akan meningkatkan pasar gula mareh maupun gula aren rafinasi meningkat $20 \%$ tiap tahunnya.

\section{DAFTAR PUSTAKA}

Luchsinger, H.R. 1984, The Swiss

Foundation For Technical Assitance, Zurich.

Mc Cabe, 1960, Unit Operations, 3th Ed., New York, Mc Millan Publ.

Pitojo, S, 1998, Anek Pembuatan Sale pisangs , Yogyakarta, Penerbit Kanisius.

Purnomo, H, Adiono. 1987, Ilmu Pangan, Jakarta, Penerbit Universitas Indonesia (UI Press)

Rajalakshmi, D., \& Narashiman, S., 1996. Food Antioxidants Sources Health Perspective. New Yor, Inc

Rismunandar \& Paimin, F.B., 2006. Pengolahan Sale pisang.

Said, E. G. 2000. Menguak Potensi Pengembangan Industri Hilir Perkebunan Indonesia. Makalah 
Seminar Sehari Kebijakan Industri Hilir Perkebunan di Jakarta.

Surdiatata, Shinroku Saito, 1985.

Pengetahuan Bahan Teknik, Jakarta, Pradnya Paramita
Wikantyasa, B. 1989. Satuan Operasi dalam Proses Pangan, Yogyakarta PAU Pangan Gizi, UGM. 